\title{
Mitogen-activated Protein Kinase and Its Activator Are Regulated by Hypertonic Stress in Madin-Darby Canine Kidney Cells
}

\author{
Takahito Itoh, Atsushi Yamauchi, Akiko Miyai, Kenji Yokoyama, Takenobu Kamada, Naohiko Ueda, and Yoshihiro Fujiwara
} First Department of Medicine, Osaka University School of Medicine, Suita, Japan, 565

\begin{abstract}
Madin-Darby canine kidney cells behave like the renal medulla and accumulate small organic solutes (osmolytes) in a hypertonic environment. The accumulation of osmolytes is primarily dependent on changes in gene expression of enzymes that synthesize osmolytes (sorbitol) or transporters that uptake them (myo-inositol, betaine, and taurine). The mechanism by which hypertonicity increases the transcription of these genes, however, remains unclear. Recently, it has been reported that yeast mitogen-activated protein (MAP) kinase and its activator, MAP kinase-kinase, are involved in osmosensing signal transduction and that mutants in these kinases fail to accumulate glycerol, a yeast osmolyte. No information is available in mammals regarding the role of MAP kinase in the cellular response to hypertonicity. We have examined whether MAP kinase and MAP kinase-kinase are regulated by extracellular osmolarity in Madin-Darby canine kidney cells. Both kinases were activated by hypertonic stress in a time- and osmolarity-dependent manner and reached their maximal activity within $10 \mathrm{~min}$. Additionally, it was suggested that MAP kinase was activated in a protein kinase $\mathrm{C}$-dependent manner. These results indicate that MAP kinase and MAP kinase-kinase(s) are regulated by extracellular osmolarity. (J. Clin. Invest. 1994. 93:23872392.) Key words: osmolyte $\bullet$ mitogen-activated protein kinasekinase • hyperosmolarity • protein kinase $\mathrm{C} \bullet$ transporter
\end{abstract}

\section{Introduction}

The renal medulla is the only tissue in mammals that normally undergoes large changes in osmolarity. These changes are part of the renal mechanism for producing a concentrated or diluted urine. When the medulla is hypertonic, the cells of the medulla balance the high extracellular concentration of sodium chloride by accumulating high concentrations of small organic solutes, termed osmolytes, through cellular uptake and biosynthesis (for reviews see references 1 and 2). The predomi-

Address correspondence to Atsushi Yamauchi, The First Department of Medicine, Osaka University School of Medicine, 2-2 Yamadaoka, Suita, Japan, 565.

Received for publication 4 October 1993 and in revised form 24 February 1994.

1. Abbreviations used in this paper: ERK, extracellular signal-regulated kinase; GST, glutathione $S$-transferase; MAP, mitogen-activated protein; MBP, myelin basic protein; MDCK, Madin-Darby canine kidney; MLCK, myosin light chain kinase; PKC, protein kinase C; WT, wildtype.

J. Clin. Invest.

(c) The American Society for Clinical Investigation, Inc.

$0021-9738 / 94 / 06 / 2387 / 06 \quad \$ 2.00$

Volume 93, June 1994, 2387-2392 nant renal medullary organic osmolytes are sorbitol, myo-inositol, betaine, glycerophosphorylcholine, and taurine, which do not perturb cell function, in contrast to high concentrations of electrolytes. Sorbitol is produced from glucose by the enzyme aldose reductase. $M y o$-inositol, betaine, and taurine are taken up into cells by Na-coupled transporters $(1,2)$. The cDNAs for aldose reductase and these osmolyte transporters have been isolated, cloned, and characterized (3-6). It has been shown that expression of these genes increases in response to hypertonic stress $(5,7-11)$.

Hypertonicity also increases the levels of mRNA encoding the early gene transcription factors, $E g r-1$ and c-fos in MadinDarby canine kidney (MDCK) ${ }^{1}$ cells (12). The expression of other genes is also affected. $\mathrm{Na} / \mathrm{K}$-ATPase expression increases in response to hypertonic stress in human renal cells (13). HSP70 is induced by hypertonic stress in MDCK cells (12). Despite these studies, the signaling pathway of hypertonic stress from the extracellular environment to the nucleus remains unknown.

Mitogen-activated protein (MAP) kinase is known to be activated quickly in response to various extracellular signals, growth factors, and vasoactive peptides (for reviews see references 14-17). MAP kinase is regulated by phosphorylation of its own threonine and tyrosine residues, which is catalyzed by the upstream molecule MAP kinase-kinase (for review see reference 18). Recently, it has been reported that the yeast counterparts of MAP kinase and MAP kinase-kinase are involved in osmosensing signal transduction and that mutants in these kinases fail to grow normally in a hyperosmolar environment (19). However, no information is available regarding such a role in higher eukaryotes.

In this study, it was determined that MAP kinase and MAP kinase-kinase were regulated by extracellular osmolarity in MDCK cells. Several lines of evidence suggest that they participate in the cellular adaptation to osmotic stress in cultured renal epithelial cells.

\section{Methods}

Materials and chemicals. MDCK cells were a generous gift from the Japanese Cancer Research Resources Bank. cDNA of rat extracellular signal-regulated kinase 2 (ERK2) was cloned from a rat cDNA library by PCR as described previously (20). cDNA of the kinase-negative ERK2 (ERK2-K52R), whose lysine-52 was substituted with arginine, was prepared by site-directed point mutagenesis using wild-type ERK2 (ERK2-WT) as a template, as described previously (21). Each cDNA was constructed into pGEX-2T (Pharmacia LKB Biotechnology Inc., Piscataway, NJ), and then glutathione $S$-transferase (GST)-ERK2 fusion proteins, GST-ERK2-WT and GST-ERK2-K52R, were expressed using Escherichia coli JM109. Each kinase fusion protein was purified as described previously $(20)$ and stored at $-80^{\circ} \mathrm{C}$ until use. The rat cDNA library was a generous gift from Y. Takai (Kobe University, Kobe, Japan ). DME, raffinose, cytochalasin $B$, myelin basic protein (MBP), histone (type III-S), and protein A-Sepharose CL-4B were purchased from Sigma Immunochemicals (St. Louis, MO). A protein 
kinase inhibitor, staurosporin, was purchased from Kyowa Medex Co., Ltd., (Tokyo, Japan). An inhibitor of myosin light chain kinase (MLCK), ML-9, was purchased from BIOMOL Research Labs Inc. (Plymouth Meeting, PA). Anti-MAP kinase monoclonal antibody was purchased from Zymed Laboratories, Inc. (South San Francisco, CA). Other chemicals were from commercial sources.

Cell culture and stimulation. MDCK cells were cultured in DME supplemented with $10 \% \mathrm{FCS}, 50 \mathrm{U} / \mathrm{ml}$ of penicillin, and $50 \mu \mathrm{g} / \mathrm{ml}$ of streptomycin equilibrated with $5 \% \mathrm{CO}_{2} / 95 \%$ air at $37^{\circ} \mathrm{C}$. Cells were passaged and grown to $80 \%$ confluent state and then cultured in serumfree DME for $48 \mathrm{~h}$. After rinsing twice with buffer A ( $10 \mathrm{mM}$ Hepes [pH 7.4], $130 \mathrm{mM} \mathrm{NaCl}, 5.4 \mathrm{mM} \mathrm{KCl}, 1.2 \mathrm{mM} \mathrm{CaCl}, 1.2 \mathrm{mM}$ $\mathrm{MgSO}_{4}, 0.1 \%$ dialyzed BSA), MDCK cells were incubated with buffer $A$ for 60 min and then treated with buffer $A$ that was made hypertonic by adding sodium chloride or raffinose for the time indicated. For depletion of protein kinase C (PKC), cells in medium were treated with $130 \mathrm{nM}$ of PMA for $16 \mathrm{~h}$. For the experiments using staurosporin, ML-9, or cytochalasin B, cells were incubated in buffer A supplemented with these compounds at the indicated concentrations for 30 $\mathrm{min}$ and then exposed to hypertonic stress in their presence. All experiments were performed using 25-30 passages of MDCK cells.

Immunoblotting and immunoprecipitation. Immunoblotting and immunoprecipitation of MAP kinase were performed as described previously with a slight modification $(22,23)$. To detect signals of immunoblotting, biotin-labeled goat anti-mouse IgG and avidin/biotin system were used (Vector Labs, Inc., Burlingame, CA). For immunoprecipitation, cells were scraped off in $1 \%$ SDS, $10 \mathrm{mM}$ Tris $/ \mathrm{HCl}$, pH 7.5, and boiled at $100^{\circ} \mathrm{C}$ for $5 \mathrm{~min}$. After sonication, nuclei were removed by brief centrifugation and an aliquot of the supernatant was diluted to a final concentration of $150 \mathrm{mM} \mathrm{NaCl}, 10 \mathrm{mM}$ Tris $/ \mathrm{HCl}$ ( $\mathrm{pH} 7.4$ ), $1 \%$ Triton X-100, 0.1\% SDS, 0.5\% NP-40, 1 mM EDTA, 1 mM EGTA, 0.2 mM sodium orthovanadate, $2 \mu \mathrm{M} p$-amidinophenylmethanesulfonyl fluoride. This was used as the cell lysate. Immunoprecipitation was carried out by sequentially incubating the cell lysate with anti-MAP kinase antibody at $4^{\circ} \mathrm{C}$ for $1 \mathrm{~h}$, with anti-mouse IgG (Zymed Laboratories, Inc.) at $4^{\circ} \mathrm{C}$ for $1 \mathrm{~h}$, and then with protein A-Sepharose CL-4B at $4^{\circ} \mathrm{C}$ for $30 \mathrm{~min}$. After centrifugation, the precipitate was washed and used as the immunoprecipitate.

Preparation of cytosol fraction. After the treatment of cells with hypertonic buffer A, culture dishes were transferred quickly on ice, and the buffer was aspirated thoroughly. Cells were scraped off with 500 $\mu \mathrm{l} / 10$-cm dish of ice-cold freshly prepared homogenizing buffer (20 $\mathrm{mM}$ Tris/ $\mathrm{HCl}$ [pH 7.4], 2 mM EGTA, $10 \mathrm{mM} \beta$-glycerophosphate, 1 $\mathrm{mM}$ sodium orthovanadate, $1 \mathrm{mM}$ DTT, $1 \mu \mathrm{M} p$-amidinophenylmethanesulfonyl fluoride, aprotinin [ $100 \mathrm{KIU} / \mathrm{ml}])$. Homogenized by brief sonication, the homogenate was centrifuged at $125,000 \mathrm{~g}$ at $4^{\circ} \mathrm{C}$ for $30 \mathrm{~min}$. The supernatant was collected as the cytosol fraction and stored at $-80^{\circ} \mathrm{C}$ until use.

Assay of kinase activity. Activity of MAP kinase was measured by the in-gel kinase assay method as described previously $(24,25)$. Activity of MAP kinase-kinase was measured using recombinant MAP kinase as described previously with a slight modification $(20,26,27)$. Briefly, $20 \mu \mathrm{g}$ protein of the cytosol fraction was incubated with $500 \mathrm{ng}$ of GST-ERK2-WT in $100 \mu$ l of reaction mixture $(20 \mathrm{mM}$ Tris $/ \mathrm{HCl}$ [pH 7.4], $2 \mathrm{mM}$ EGTA, $10 \mathrm{mM} \mathrm{MgCl}, 100 \mu \mathrm{M}$ ATP) at $25^{\circ} \mathrm{C}$ for 10 min. After adding SDS sampling buffer for boiling and electrophoresis, activity of GST-ERK2 was measured by the in-gel kinase assay method. To study the effect of staurosporin on MAP kinase-kinase, the cytosol fraction was incubated with GST-ERK2-WT as described above, except that it was performed in the presence of staurosporin at the concentration indicated. To detect phosphorylation of GST-ERK2 by the cytosol fraction, $5 \mu \mathrm{g}$ of protein of the cytosol fraction was incubated with $500 \mathrm{ng}$ of GST-ERK2-WT or GST-ERK2-K52R in $50 \mu \mathrm{l}$ of reaction mixture using $100 \mu \mathrm{M}\left[\gamma-{ }^{32} \mathrm{P}\right] \mathrm{ATP}(25 \mu \mathrm{Ci} / \mathrm{ml})$ instead of nonlabeled ATP at $25^{\circ} \mathrm{C}$ for $10 \mathrm{~min}$. The sample was applied on SDSPAGE, and the dried gel was exposed to XAR film (Eastman Kodak Co., Rochester, NY). Radioactivity was measured by a bioimaging analyzer (BAS2000; Fuji Photo Film Co., Ltd., Tokyo, Japan).
Other procedures. Protein concentrations were measured as described previously (28).

\section{Results}

MAP kinase activation by hypertonic stress. MBP phosphorylating activities markedly increased in the MDCK cell lysate, when cells were incubated with buffer $A$ that was made hypertonic by adding sodium chloride to a total osmolarity of 1,000 mosmol $/ \mathrm{kg}$ of $\mathrm{H}_{2} \mathrm{O}$ at $37^{\circ} \mathrm{C}$ for $10 \mathrm{~min}$ (Fig. 1, lanes 1 and 2). Immunoblotting of the cell lysate with anti-MAP kinase monoclonal antibody showed 49- and 42-kD bands (Fig. 1, lanes 3 and 4). These kinases were exclusively immunoprecipitated from the cell lysate with the same antibody (Fig. 1, lanes 5 and 6). In addition, when histone was used as a substrate of the in-gel kinase assay, these kinases did not phosphorylate it (data not shown). For these reasons, they were identified as MAP kinases of MDCK cells. The cytosol fraction from MDCK cells that were incubated with hypertonic buffer $A$ also showed the activation of the same kinases as the cell lysate (Fig. 1, lanes 7 and 8 ). To exclude the effects of detergents, we used the cytosol fraction as the sample for the following studies. The 49-kD MAP kinase was activated by hypertonicity in a time-dependent manner. It reached its maximal activity $10 \mathrm{~min}$ after cells were exposed to hypertonic stress ( Fig. 2). Half-maximal activity was sustained at least up to $60 \mathrm{~min}$. Similar results were obtained for the 42-kD MAP kinase.

Osmolarity-dependent activation of MAP kinase. The 49KD MAP kinase was activated by hypertonic stress in a osmolarity-dependent manner (Fig. 3). This activity increased almost linearly up to $1,000 \mathrm{mosmol} / \mathrm{kg}$ of $\mathrm{H}_{2} \mathrm{O}$ by adding sodium chloride and decreased at $1,500 \mathrm{mosmol} / \mathrm{kg}$ of $\mathrm{H}_{2} \mathrm{O}$. When using raffinose to make buffer $A$ hypertonic instead of sodium chloride, MAP kinase was activated more effectively and reached its maximum at $550 \mathrm{mosmol} / \mathrm{kg}$ of $\mathrm{H}_{2} \mathrm{O}$. Similar

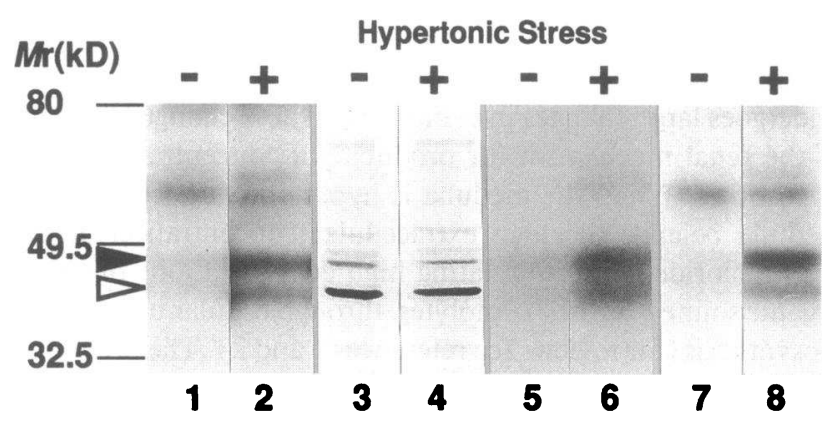

Figure 1. MAP kinase activation by hypertonic stress. MDCK cells were stimulated at $37^{\circ} \mathrm{C}$ for $10 \mathrm{~min}$ with isotonic or hypertonic buffer A. Hypertonicity was induced by adding sodium chloride to a total osmolarity of $1,000 \mathrm{mosmol} / \mathrm{kg}$ of $\mathrm{H}_{2} \mathrm{O}$. For the in-gel kinase assay, each aliquot of the sample was applied on SDS-PAGE using $10 \%$ polyacrylamide gel containing $0.5 \mathrm{mg} / \mathrm{ml}$ MBP. After renaturation of the sample, it was incubated with $\left[\gamma-{ }^{32} \mathrm{P}\right] \mathrm{ATP}$. Phosphorylated MBP was visualized by autoradiography. Anti-MAP kinase antibody was used for immunoblotting and immunoprecipitation. Lanes 1 and 2 , the in-gel kinase assay of the cell lysate; lanes 3 and 4, immunoblotting of the cell lysate; lanes 5 and 6 , the in-gel kinase assay of the immunoprecipitate from the cell lysate; lanes 7 and 8 , the in-gel kinase assay of the cytosol fraction. The black and white arrowheads represent the 49- and 42-kD MAP kinases, respectively. Molecular standards are indicated at the left side. The results are representative of three independent experiments. 

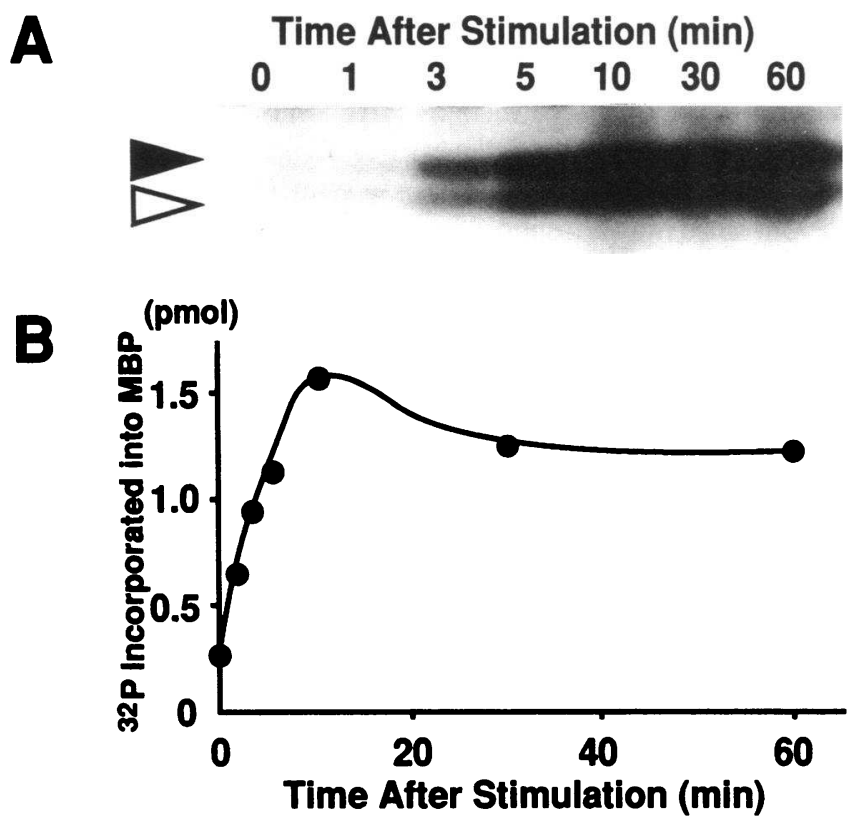

Figure 2. Time course of MAP kinase activation induced by hypertonic stress. MDCK cells were stimulated as described in the legend to Fig. 1. After the time indicated, the cytosol fraction was prepared. Phosphate-32 incorporated into MBP was measured by a bioimaging analyzer. $(A)$ Autoradiography of the in-gel kinase assay. The black and white arrowheads indicate 49- and 42-kD MAP kinases, respectively. ( $B$ ) Radioactivity of phosphate-32 incorporated into MBP by 49-kD MAP kinase. The results are representative of three independent experiments.

results were obtained for the 42-kD MAP kinase (data not shown).

MAP kinase-kinase activation by hypertonic stress. Because of its molecular mass of $70 \mathrm{kD}$, a recombinant MAP kinase, GST-ERK2, is easy to distinguish from endogenous MAP kinases in polyacrylamide gel $(20,27)$. Since it shows no basal activity, the change of its activity is detected very sensitively $(20,27)$. For these reasons, GST-ERK 2 is very useful for detecting the activity of MAP kinase-kinase $(20,27)$. Incubated with the cytosol fraction from cells exposed to hypertonic stress, the activated GST-ERK2-WT was detected by the in-gel kinase assay (Fig. $4 \mathrm{~A}$ ). This indicated that a factor(s) activating GST-ERK2-WT was induced by hypertonic stress. This factor(s) showed its maximal activity when the cytosol fraction was prepared from cells exposed to hypertonic stress for $10 \mathrm{~min}$ (Fig. 4, $A$ and $C$ ). Next, we examined whether GST-ERK2 was phosphorylated or not under the same condition, because its activity was dependent upon its own phosphorylation catalyzed by MAP kinase-kinase(s) (20). GST-ERK-WT was phosphorylated in parallel with its activity when it was incubated with the cytosol fraction from cells exposed to hypertonic stress for the time indicated (Fig. $4 B$ ). GST-ERK2-K52R, which was disrupted on its ATP-binding site and had no kinase activity (data not shown) (21), was also phosphorylated by incubation with the cytosol fraction in the same way (Fig. $4 B$ ). Therefore, the phosphorylation of GST-ERK2 was not due to autophosphorylation. These results indicated that this factor(s) was a kinase, namely MAP kinase-kinase(s).

MAP kinase activation was reversible. To confirm whether MAP kinase activity was regulated by extracellular osmolarity, hypertonic buffer A was changed to an isotonic buffer $30 \mathrm{~min}$ after cells were exposed to hypertonic stress. The activity of 49-kD MAP kinase decreased quickly and returned to near basal levels at 30 min after the shift (Fig. 5). MAP kinase was activated when cells were reexposed to hypertonic buffer $A$ at $30 \mathrm{~min}$ (Fig. 5). This result excluded the possibility that the change of MAP kinase activity was due to permanent cell damage. Similar results were obtained for the 42-kD MAP kinase (data not shown).

Effects of various inhibitors on MAP kinase activation. Some extracellular signals activate MAP kinase through PKC (for review see reference 15). To determine whether MAP kinase and MAP kinase-kinase(s) of MDCK cells were activated by hypertonic stress through PKC, the experiment was performed in the presence or absence of PKC. When PKC was depleted by incubation of cells with $130 \mathrm{nM}$ PMA for $16 \mathrm{~h}$, the activation of 49-kD MAP kinase by hypertonic stress was abolished completely (Fig. $6 \mathrm{~A}$ ). When cells were treated with staurosporin, an inhibitor of PKC, for 30 min and stimulated with hypertonic buffer A containing staurosporin, the activation of 49-kD MAP kinase was inhibited in a dose-dependent manner (Fig. $6 \mathrm{~B}$ ). The $50 \%$ inhibitory concentration was $\sim 10^{-7} \mathrm{M}$. Additionally, staurosporin inhibited MAP kinase activation induced by the cytosol fraction of cells exposed to hypertonic stress as well, and the $50 \%$ inhibitory concentration was also $\sim 10^{-7} \mathrm{M}$ (Fig. $6 \mathrm{~B}$ ). An inhibitor of MLCK, ML-9, showed no prevention of MAP kinase activation. Cytochalasin B $(20 \mu \mathrm{M})$ also had no effect on MAP kinase activation (Fig. 6 $B)$. Similar results were obtained for the 42-kD MAP kinase (data not shown).

\section{Discussion}

Renal medullary cells adapt to hyperosmolar environments under the physiological conditions that are part of the mecha-

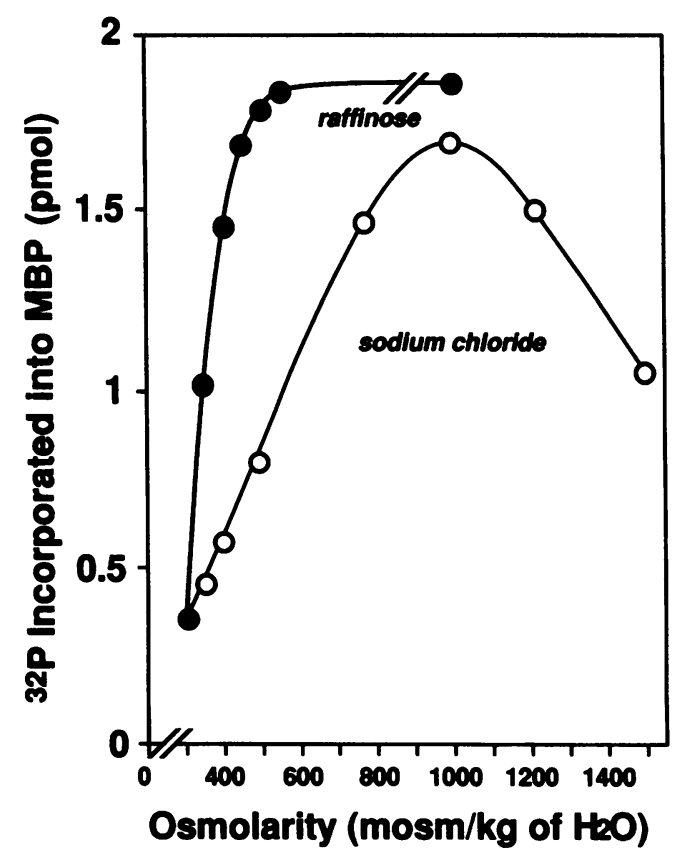

Figure 3. Osmolarity-dependency of 49-kD MAP kinase activation induced by hypertonic stress. MDCK cells were stimulated with buffer A made hypertonic by adding sodium chloride or raffinose to the osmolarity indicated. After $10 \mathrm{~min}$, the cytosol fraction was prepared, and MAP kinase activity was assayed as described in the legend to Fig. 1. The results are representative of three independent experiments. 

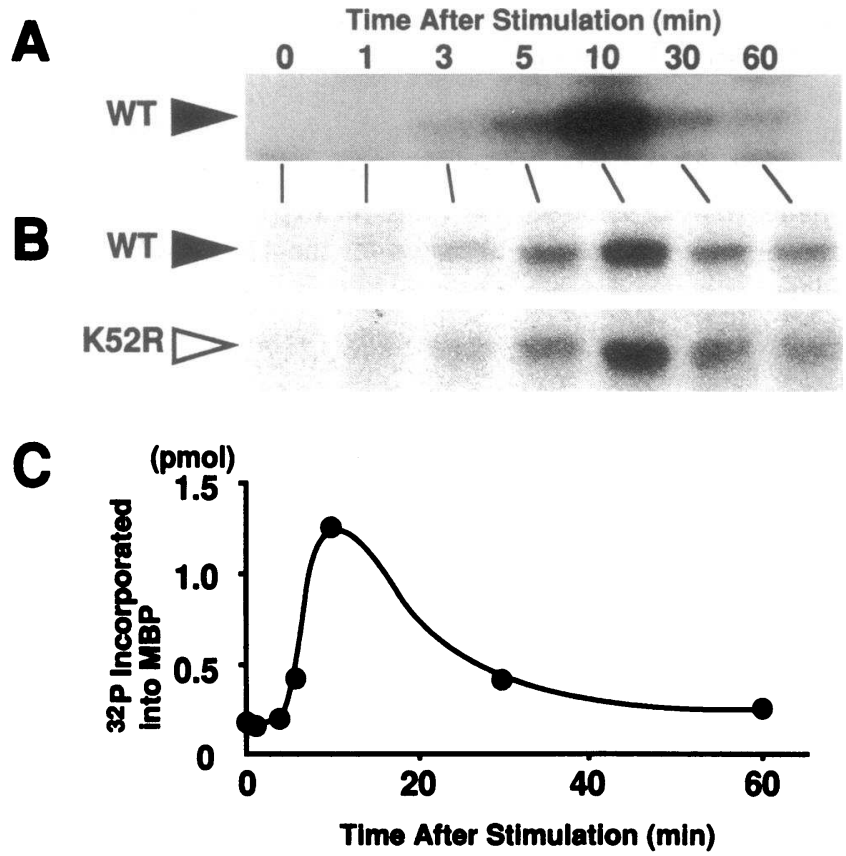

Figure 4. Activation of MAP kinase-kinase by hypertonic stress. $10 \mu \mathrm{g}$ protein of the cytosol fraction was incubated with $500 \mathrm{ng}$ of GSTERK2-WT or $-\mathrm{K} 52 \mathrm{R}$ in the reaction mixture at $25^{\circ} \mathrm{C}$ for $10 \mathrm{~min}$. $(A)$ Phosphorylated MBP by GST-ERK2 was detected by the in-gel kinase assay method. ( $B$ ) Phosphate-32 incorporated into GST-ERK2. The cytosol fraction was incubated with GST-ERK2-WT or -K52R in the presence of $\left[\gamma-{ }^{32} \mathrm{P}\right] A T P$. Each sample was applied on SDS-PAGE using $10 \%$ polyacrylamide gel without MBP, and autoradiography was performed. $(C)$ Radioactivity of phosphate-32 incorporated into MBP by GST-ERK2-WT. Black and white arrowheads indicate GST-ERK2-WT and -K52R, respectively. The results are representative of three independent experiments.

nism of producing a concentrated urine $(1,2)$. A variety of cell responses to hypertonic stress has been reported $(1,2)$, and the responses are generally divided into two categories. One is the initial response such as the regulation of cell volume, which does not need gene expression, and the other is the induction of mRNA levels and protein products of osmoregulatory genes such as osmolyte transporters. Levels of mRNA encoding early gene transcription factors, $E g r-1$ and c- fos, are also induced by hypertonic stress (12). Until recently, however, little information was available regarding the mechanism by which the signal of extracellular osmolarity reached the nucleus to regulate the expression of these genes.

MAP kinase and its activator(s), MAP kinase-kinase(s), are thought to be key enzymes that transduce the extracellular signals to the nucleus, since they are activated by various growth factors in vitro and in a cell cycle-dependent manner in vivo (for reviews see references $14,15,18$ ). Very recently, it has been reported that an MAP kinase homologue of budding yeast, HOG1, and its activator, PBS2, play an important role in the osmosensing pathway (19). Mutants lacking HOG1 or PBS2 showed abnormal cell growth on hyperosmolar medium (19). In this paper, we report the regulation of MAP kinase and MAP kinase-kinase by hypertonic stress in a renal epithelial cell line, MDCK cells.

By immunoblotting and immunoprecipitation with antiMAP kinase antibody, we detected two bands both in the lysate and cytosol fraction from hypertonicity-treated MDCK cells
(Fig. 1). The molecular masses were $\sim 49$ and $42 \mathrm{kD}$, respectively. These enzymes phosphorylated MBP, but not histone. Therefore, we identified them as MAP kinases of MDCK cells. Another band with a molecular mass of $\sim 55 \mathrm{kD}$ was detected in the cell lysate by the in-gel kinase assay (Fig. 1, lanes 1 and 2), but since they phosphorylated histone other than MBP and were not affected by hypertonic stress, they were not identified in this study. It has been reported that MAP kinase has several isozymes in various mammalian cells $(14,15)$, which are referred to as the ERK family. Both MAP kinases of MDCK cells most likely belong to the ERK family. They showed maximal activity $10 \mathrm{~min}$ after exposure to hypertonic stress (Fig. 2), and this peak time is comparable with the previous studies using growth factors $(14,15)$. MAP kinases of MDCK cells were activated in an osmolarity-dependent manner, which was linear up to $1,000 \mathrm{mosmol} / \mathrm{kg}$ of $\mathrm{H}_{2} \mathrm{O}$ when the osmolarity was adjusted by the addition of sodium chloride (Fig. 3 ). The activity of MAP kinase decreased to $60 \%$ of the maximum at 1,500 mosmol $/ \mathrm{kg}$ of $\mathrm{H}_{2} \mathrm{O}$, which seemed to be toxic for cultured cells. Raffinose, a neutral sugar, activated MAP kinases more effectively, about twice as much at $500 \mathrm{mosmol} / \mathrm{kg}$ of $\mathrm{H}_{2} \mathrm{O}$ (Fig. 3). Regarding the induction of an osmolyte transporter gene by hypertonicity, similar differences induced by raffinose and sodium chloride have been reported (10). The mechanism of this phenomenon remains to be examined.

MAP kinase is known to be regulated by its own phosphorylation that is catalyzed by MAP kinase-kinase. A recombinant MAP kinase, GST-ERK2-WT, was phosphorylated and activated by the cytosol fraction from hypertonicity-treated cells (Fig. 4, $A-C$ ). Autophosphorylation of GST-ERK2-WT was denied by the experiment using GST-ERK2-K52R with no kinase activity (Fig. $4 \mathrm{~B}$ ). Because we used GST-ERK2 as a substrate for MAP kinase-kinase assay in excess of endogenous MAP kinases, which were quantified by Coomassie brilliant blue protein staining of gel (data not shown), endogenous MAP kinases were unlikely to competitively inhibit the activation and phosphorylation of GST-ERK2-WT catalyzed by MAP kinase-kinase. In fact, endogenous MAP kinases in the cytosol fraction were not activated further by incubation with

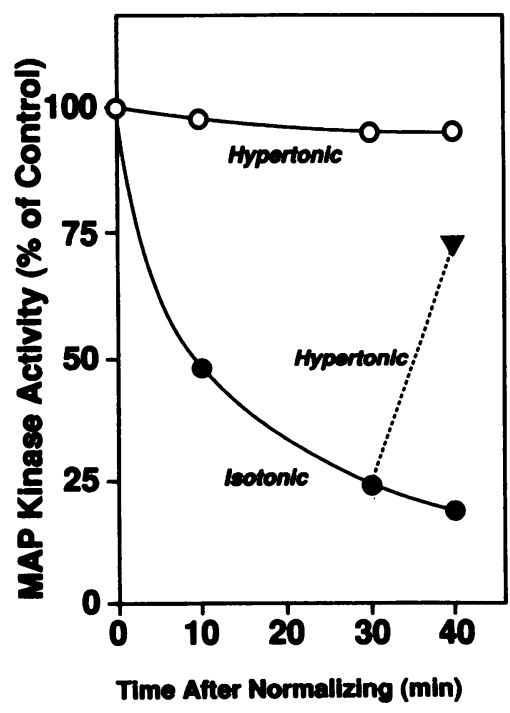

Figure 5. Effect of normalizing the extracellular osmolarity on MAP kinase activity. Hypertonic buffer A was changed to isotonic buffer A 30 min after cells were exposed to hypertonic stress (sodium chloride, a final osmolarity of 1,000 mosmol $/ \mathrm{kg}$ of $\mathrm{H}_{2} \mathrm{O}$ ). 30 min after normalizing osmolarity, cells under isotonic condition were reexposed to hypertonic stress. At the times indicated, the cytosol fraction was prepared, and MAP kinase activity was assayed by the in-gel kinase assay

method. The activity at 0 min after switching back was designated as $100 \%$. The results are representative of three independent experiments. 


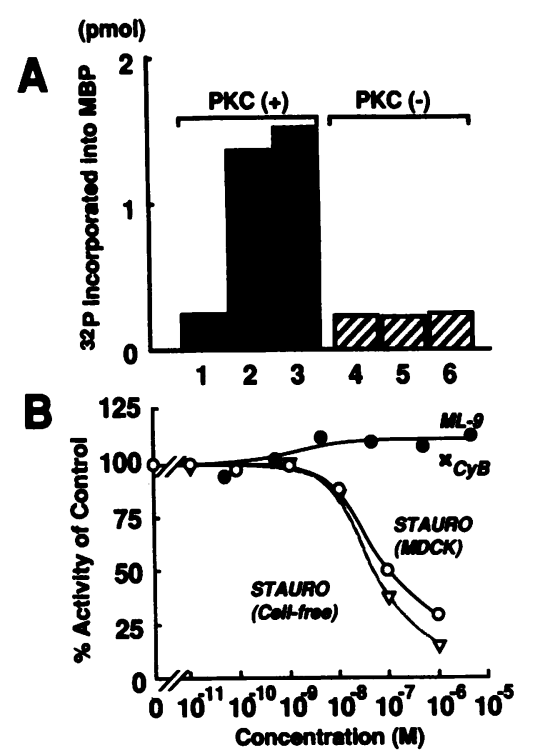

Figure 6. Effects of PMA, staurosporin, and ML-9 on 49-kD MAP kinase activation induced by hypertonic stress. $(A)$ Effect of PMA. MDCK cells were cultured in the presence or absence of $130 \mathrm{nM}$ PMA, DME, 0.1\% BSA at $37^{\circ} \mathrm{C}$ for $16 \mathrm{~h}$ under $5 \% \mathrm{CO}_{2}$. After washing, they were stimulated for 10 min with buffer $A$ alone (lanes 1 and 4), and supplemented with sodium chloride (a final osmolarity of 1,000 mosmol $/ \mathrm{kg}$ of $\mathrm{H}_{2} \mathrm{O}$ ) (lanes 2 and 5) or 150 nM PMA (lanes 3 and

6). (B) Effects of staurosporin, ML-9, and cytochalasin B. MDCK cells were treated with the various concentrations of staurosporin, ML-9, or cytochalasin B for $30 \mathrm{~min}$ and then exposed to buffer A made hypertonic by adding sodium chloride to $1,000 \mathrm{mosmol} / \mathrm{kg}$ of $\mathrm{H}_{2} \mathrm{O}$ in the presence of each inhibitor. MAP kinase activity was measured by the in-gel kinase assay method, and in $B$, the activity in the absence of inhibitors was designated as $100 \%$. STAURO (MDCK), the effect of staurosporin on hypertonicity-induced 49-kD MAP kinase activation in MDCK cells; STAURO (Cell-free), the effect of staurosporin on GST-ERK2 activation. Staurosporin was added to the cytosol fraction from cells exposed to hypertonicity in the absence of staurosporin; $M L-9$, the effect of ML-9 on hypertonicity-induced MAP kinase activation in MDCK cells; $C y B$, the effect of cytochalasin B on hypertonicity-induced MAP kinase activation in MDCK cells. The results are representative of three independent experiments.

GST-ERK2 (data not shown), and the time course of GSTERK2 activation was so different from that of MAP kinase that endogenous MAP kinase did not seem to contribute to the phosphorylation and activation of GST-ERK2. These results indicate that MAP kinase-kinase(s) in MDCK cells was activated by hypertonic stress.

Compared with MAP kinase, MAP kinase-kinase seemed to be activated more slowly and transiently (Fig. 4). This might be partly because of the higher basal activity of endogenous MAP kinase. Nishida's group (29) has reported that MAP kinase phosphorylates and activates MAP kinase-kinase and proposed a positive feedback loop between the two. If true, this might explain the accelerated activation of MAP kinase-kinase. Furthermore, since active MAP kinase-kinase catalytically phosphorylates and activates MAP kinase, the initial response of MAP kinase-kinase may be small but enough to activate MAP kinase. Alternatively, there is a possibility that unidentified MAP kinase activator, which may be difficult to detect by our assay system, may be involved in the initial activation of MAP kinase. Once MAP kinase was activated by hypertonicity, extracellular hypertonicity was essential to maintain its activation, but not MAP kinase-kinase (Figs. 4 and 5). These results suggest that MAP kinase is regulated by unidentified inactivators, possibly protein phosphatases, rather than MAP kinase-kinase in the later stages.

To examine the involvement of other signaling molecules, pharmacological studies were performed. MAP kinases of
MDCK cells were markedly activated by $150 \mathrm{nM}$ PMA as well as by hypertonic stress. Activation by $150 \mathrm{nM}$ PMA or by hypertonicity were both abolished when PKC was depleted by the treatment of cells with $130 \mathrm{nM}$ PMA for $16 \mathrm{~h}$ (Fig. $6 \mathrm{~A}$ ). This suggests that hypertonic stress activated MAP kinases of MDCK cells in a PKC-dependent manner. Staurosporin, which is sometimes used as an inhibitor of PKC, did not establish that PKC was involved in hypertonicity-induced MAP kinase activation because staurosporin inhibited a range of kinases including MAP kinase-kinase (Fig. $6 B$ ) $(21,26)$.

After osmotic swelling or shrinking in an anisosmotic environment, many cells recover their original volume by adjusting the concentration of intracellular inorganic ions and osmolytes, which are referred to as regulatory volume increase or decrease (1). The change of cell volume activates stretch-activated ion channels ( 30$)$, and it is postulated that the sensitivity of these channels is regulated by submembrane cytoskeletal elements (31). It is reported that hypertonic stress induces the phosphorylation of myosin light chain in cultured mesangial cells (32). In light of these studies, we examined whether MLCK was involved in the pathway of hypertonicity-induced MAP kinase activation. MDCK cells were stimulated with hypertonic stress in the presence of ML-9, an inhibitor of MLCK; no inhibition was observed in hypertonicity-induced MAP kinase activation (Fig. $6 \mathrm{~B}$ ). We also examined the effect of cytochalasin B, an inhibitor of microfilaments, on MAP kinase activation. When MDCK cells were treated with $20 \mu \mathrm{M}$ of cytochalasin B, it showed no effect on MAP kinase activation. Although cytochalasin B inhibits the function of ion transporters in various cells $(10,33,34)$, it is still unknown whether it inhibits the expression of osmolyte transporters. At least, it is unlikely that microfilaments associate directly to MAP kinase activation.

There are several lines of evidence showing that MAP kinase regulates gene transcription and protein translation directly or indirectly. First, MAP kinase activation is dependent upon cell cycle $(14,15)$. Second, MAP kinase is activated by various growth factors $(14,15)$. Third, MAP kinase phosphorylates transcription factors, c-jun and c-myc in vitro (35). Fourth, MAP kinase translocates from cytoplasm to the nucleus in response to growth factors (36). Fifth, MAP kinase phosphorylates and activates S6 kinase II that is thought to regulate the translational efficiency of $40 \mathrm{~S}$ ribosomal subunits (14). In light of these findings, a yeast study (19) and our results, it is hypothesized that hypertonicity-induced MAP kinases of MDCK cells may regulate transcription and/or translation of osmolarity-associated genes such as osmolyte transporters and osmolyte synthetases. Alternatively, it has also been reported that a variety of vasoactive peptides activate MAP kinases in cultured cells such as vascular smooth muscle cells and renal mesangial cells $(16,17)$. Since they are low-turnover cells in vivo, it is likely that MAP kinase does not regulate transcription or translation, but rather regulates cell physiological functions such as vasoconstriction and mesangial contraction. Anisosmotic stress induces phosphorylation of $\mathrm{Na} / \mathrm{K} /$ $2 \mathrm{Cl}$ cotransporter and $\mathrm{Na} / \mathrm{K}$ exchanger that are necessary for regulatory volume increase $(37,38)$. MAP kinase in MDCK cells may also regulate the functions of osmoregulatory gene products directly or indirectly by their phosphorylation, but this has not yet been studied.

Although our results together with previous studies suggest that MAP kinase-kinase and MAP kinase are closely associated 
with the regulation of osmoregulatory genes or their products, additional works will be required to confirm a direct relationship.

\section{Acknowledgments}

We thank Dr. Yoshimi Takai (Kobe University, Kobe, Japan) for kindly providing the rat cDNA library, and Dr. Joseph S. Handler (Johns Hopkins University, Baltimore, MD) for helpful advice.

This research was supported by grants-in-aid for Scientific Research from the Ministry of Education, Science, and Culture, Japan.

\section{References}

1. Chamberlin, M. E., and K. Strange. 1989. Anisosmotic cell volume regulation: a comparative view. Am. J. Physiol. 257:C159-C173.

2. Garcia-Perez, A., and M. B. Burg. 1991. Renal medullary organic osmolytes. Physiol. Rev. 7:1081-1115.

3. Garcia-Perez, A., B. Martin, H. R. Murphy, S. Uchida, H. Murer, J. B. D. Cowley, J. S. Handler, and M. B. Burg. 1991. Molecular cloning of cDNA coding for kidney aldose reductase. J. Biol. Chem. 264:16815-16821.

4. Kwon, H. M., A. Yamauchi, S. Uchida, A. S. Preston, A. Garcia-Perez, M. B. Burg, and J. S. Handler. 1992. Cloning of the cDNA for a $\mathrm{Na}^{+} / m y 0$-inositol cotransporter, a hypertonicity stress protein. J. Chem. Biol. 267:6297-6301. 5. Uchida, S., H. M. Kwon, A. Yamauchi, A. S. Preston, F. Marumo, and J. S. Handler. 1992. Molecular cloning of the cDNA for an MDCK cell $\mathrm{Na}^{+}$- and $\mathrm{Cl}^{-}$-dependent taurine transporter that is regulated by hypertonicity. Proc. Natl. Acad. Sci. USA. 89:8230-8234.

6. Yamauchi, A., S. Uchida, H. M. Kwon, A. S. Preston, R. B. Robey, A. Garcia-Perez, M. B. Burg, and J. S. Handler. 1992. Cloning of a $\mathrm{Na}^{+}$- and Cl${ }^{-}$-dependent betaine transporter that is regulated by hypertonicity. J. Biol. Chem 267:649-652.

7. Bondy, C. A., S. L. Lightman, and S. L. Lightman. 1989. Developmental and physiological regulation of aldose reductase mRNA expression in renal medulla. Mol. Endocrinol. 3:1409-1416.

8. Cowley, B. D., J. D. Ferraris, D. Carper, and M. B. Burg. 1990. In vivo osmoregulation of aldose reductase mRNA, protein, and sorbitol in renal medulla. Am. J. Physiol. 258:F154-F161.

9. Smardo, F. L., Jr., M. B. Burg, and A. Garcia-Perez. 1990. Kidney aldose reductase gene transcription is osmotically regulated. J. Am. Soc. Nephrol. 1:744a. (Abstr.)

10. Yamauchi, A., S. Uchida, A. S. Preston, H. M. Kwon, and J. S. Handler 1993. Hypertonicity stimulates transcription of gene for $\mathrm{Na}^{+}-m y o$-inositol cotransporter in MDCK cells. Am. J. Physiol. 264:F20-F23.

11. Uchida, S., A. Yamauchi, A. S. Preston, H. M. Kwon, and J. S. Handler 1993. Medium tonicity regulates expression of the $\mathrm{Na}^{+}$- and $\mathrm{Cl}^{-}$-dependent betaine transporter in Madin-Darby canine kidney cells by increasing transcription of the transporter gene. J. Clin. Invest. 91:1604-1607.

12. Cohen, D. M., J. C. Wasserman, and S. R. Gullans. 1991. Immediate early gene and HSP70 expression in hyperosmotic stress in MDCK cells. Am. J. Physiol. 261:C594-C601.

13. Yordy, M. R., and J. W. Bowen. 1993. Na, K-ATPase expression and cell volume during hypertonic stress in human renal cells. Kidney Int. 43:940-948.

14. Sturgill, T. W., and J. Wu. 1991. Recent progress in characterization of protein kinase cascades for phosphorylation of ribosomal protein S6. Biochim. Biophys. Acta. 1092:350-357.

15. Cobb, M. H., T. G. Boulton, and D. J. Robbins. 1991. Extracellular signal-regulated kinases: ERKs in progress. Cell Regul. 2:965-978.

16. Simonson, M. S., Y. Wang, J. M. Jones, and M. J. Dunn. 1992. Protein kinase $C$ regulates activation of mitogen-activated protein kinase and induction of proto-oncogene c-fos by endothelin-1. J. Cardiovasc. Pharmacol. 20(Suppl. 12):S29-S32.

17. Tsuda, T., Y. Kawahara, Y. Ishida, M. Koide, K. Shii, and M. Yokoyama. 1992. Angiotensin II stimulates two myelin basic protein/microtubule-associated protein 2 kinases in cultured vascular smooth muscle cells. Circ. Res. 71:620 630.

18. Blenis, J. 1993. Signal transduction via the MAP kinases: proceed at your own RSK. Proc. Natl. Acad. Sci. USA. 90:5889-5892.

19. Brewster, J. L., T. Valoir, N. D. Dwyer, E. Winter, and M. C. Gustin. 1993. An osmosensing signal transduction pathway in yeast. Science (Wash. DC). 259:1760-1763.

20. Itoh, T., K. Kaibuchi, T. Masuda, T. Yamamoto, Y. Matsuura, A. Maeda, K. Shimizu, and Y. Takai. 1993. The post-translational processing of ras p21 is critical for its stimulation of mitogen-activated protein kinase. J. Biol. Chem. 268:3025-3028.

21. Wu, J., A. J. Rossomando, J.-H. Her, R. D. Vecchio, M. J. Weber, and T. W. Sturgill. 1991. Autophosphorylation in vitro of recombinant 42-kilodalton mitogen-activated protein kinase on tyrosine. Proc. Natl. Acad. Sci. USA. 88:9508-9512.

22. Oemar, B. S., N. M. Law, and S. A. Rosenzweig. 1991. Insulin-like growth factor- 1 induces tyrosyl phosphorylation of nuclear proteins. J. Biol. Chem. 266:24241-24244.

23. Pomerance, M., F. Schweighoffer, B. Tocque, and M. Pierre. 1992. Stimulation of mitogen-activated protein kinase by oncogene ras p21 in Xenopus oocytes. J. Biol. Chem. 267:16155-16160.

24. Kameshita, I., and H. Fujisawa. 1989. A sensitive method for detection of calmodulin-dependent protein kinase II activity in sodium dodecyl sulfate-polyacrylamide gel. Anal. Biochem. 183:139-143.

25. Gotoh, Y., E. Nishida, S. Matsuda, N. Shiina, H. Kosako, K. Shiokawa, T. Akiyama, K. Ohta, and H. Sakai. 1991. In vitro effects on microtubule dynamics of purified Xenopus M phase-activated MAP kinase. Nature (Lond.). 349:251254.

26. Rossomando, A., J. Wu, M. J. Weber, and T. W. Sturgill. 1992. The phorbol ester-dependent activator of the mitogen-activated protein kinase p42 mapk is a kinase with specificity for the threonine and tyrosine regulatory sites. Proc. Natl. Acad. Sci. USA. 89:5221-5225.

27. Itoh, T., K. Kaibuchi, T. Masuda, T. Yamamoto, Y. Matsuura, A. Maeda, K. Shimizu, and Y. Takai. 1993. A protein factor for ras p21-dependent activation of mitogen-activated protein (MAP) kinase through MAP kinase kinase. Proc. Natl. Acad. Sci. USA. 90:975-979.

28. Bradford, M. M. 1976. A rapid and sensitive method for the quantitation of microgram quantities of protein utilizing the principle of protein-dye binding. Anal. Biochem. 72:248-254.

29. Matsuda, S., Y. Gotoh, and E. Nishida. 1993. Phosphorylation of Xenopus mitogen-activated protein (MAP) kinase kinase by MAP kinase kinase kinase and MAP kinase. J. Biol. Chem. 268:3277-3281.

30. Lohr, J. W., and J. J. Grantham. 1986. Isovolumetric regulation of isolated S2 proximal tubules in anisotonic media. J. Clin. Invest. 78:1165-1172.

31. Guharay, F., and F. Sachs. 1984. Stretch-activated single ion channel currents in tissue-cultured embryonic chick skeletal muscle. J. Physiol. (Lond.). 352:685-701.

32. Takeda, M., T. Homma, M. D. Breyer, N. Horiba, R. L. Hoover, S. Kawamoto, I. Ichikawa, and V. Kon. 1993. Volume and agonist-induced regulation of myosin light-chain phosphorylation in glomerular mesangial cells. Am. J. Physiol. 264:F421-F426.

33. Segal, S., S. M. Hwang, J. Stern, and D. Pleasure. 1984. Inositol uptake by cultured isolated rat Schwann cells. Biochem. Biophys. Res. Commun. 120:486492.

34. Biden, T. J., and C. B. Wollheim. 1986. Active transport of myo-inositol in rat pancreatic islets. Biochem. J. 236:889-893.

35. Leevers, S. J., and C. J. Marshall. 1992. MAP kinase regulation, the oncogene connection. Trends Cell Biol. 2:283-286.

36. Chen, R.-H., C. Sarnecki, and J. Blenis. 1992. Nuclear localization and regulation of erk- and rsk-encoded protein kinases. Mol. Cell. Biol. 12:915-927.

37. Grinstein, S., J. D. Goetz-Smith, D. Stewart, B. J. Beresford, and A. Mellors. 1986. Protein phosphorylation during activation of $\mathrm{Na}^{+} / \mathrm{K}^{+}$exchange by phorbol esters and by osmotic shrinking. J. Biol. Chem. 261:8009-8016.

38. Pewitt, E. B., R. S. Hegde, M. Haas, and H. C. Palfrey. 1990. The regulation of $\mathrm{Na} / \mathrm{K} / 2 \mathrm{Cl}$ cotransport and bumetanide binding in avian erythrocytes by protein phosphorylation and dephosphorylation. J. Biol. Chem. 265:2074720756. 